
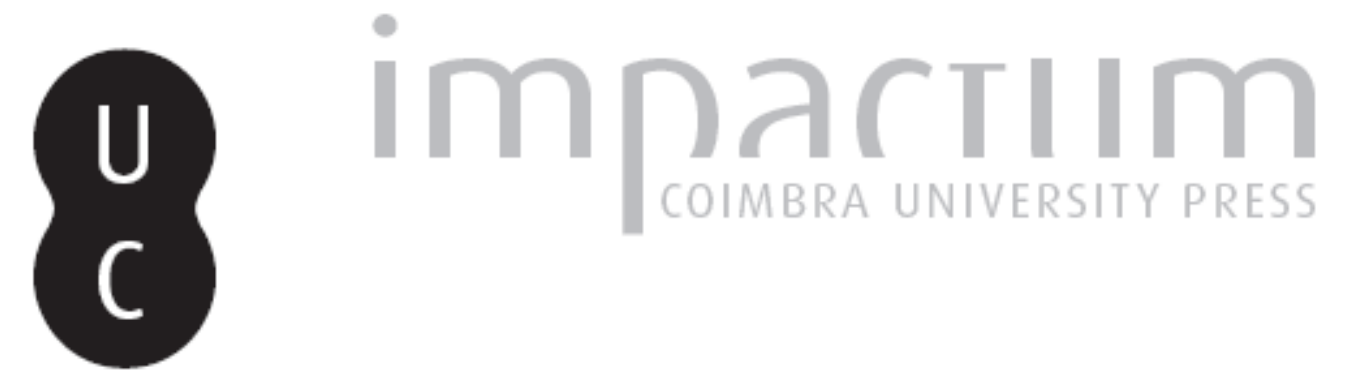

\title{
A disciplina de Epigrafia na Faculdade de Letras de Coimbra
}

Autor(es): $\quad$ Encarnação, José d'

Publicado por: Faculdade de Letras da Universidade de Coimbra

URL persistente:

URI:http://hdl.handle.net/10316.2/32407

DOI:

DOI:http://dx.doi.org/10.14195/0870-4112_9_4

Accessed : $\quad$ 26-Apr-2023 13:20:47

A navegação consulta e descarregamento dos títulos inseridos nas Bibliotecas Digitais UC Digitalis, UC Pombalina e UC Impactum, pressupõem a aceitação plena e sem reservas dos Termos e Condições de Uso destas Bibliotecas Digitais, disponíveis em https://digitalis.uc.pt/pt-pt/termos.

Conforme exposto nos referidos Termos e Condições de Uso, o descarregamento de títulos de acesso restrito requer uma licença válida de autorização devendo o utilizador aceder ao(s) documento(s) a partir de um endereço de IP da instituição detentora da supramencionada licença.

Ao utilizador é apenas permitido o descarregamento para uso pessoal, pelo que o emprego do(s) título(s) descarregado(s) para outro fim, designadamente comercial, carece de autorização do respetivo autor ou editor da obra.

Na medida em que todas as obras da UC Digitalis se encontram protegidas pelo Código do Direito de Autor e Direitos Conexos e demais legislação aplicável, toda a cópia, parcial ou total, deste documento, nos casos em que é legalmente admitida, deverá conter ou fazer-se acompanhar por este aviso. 

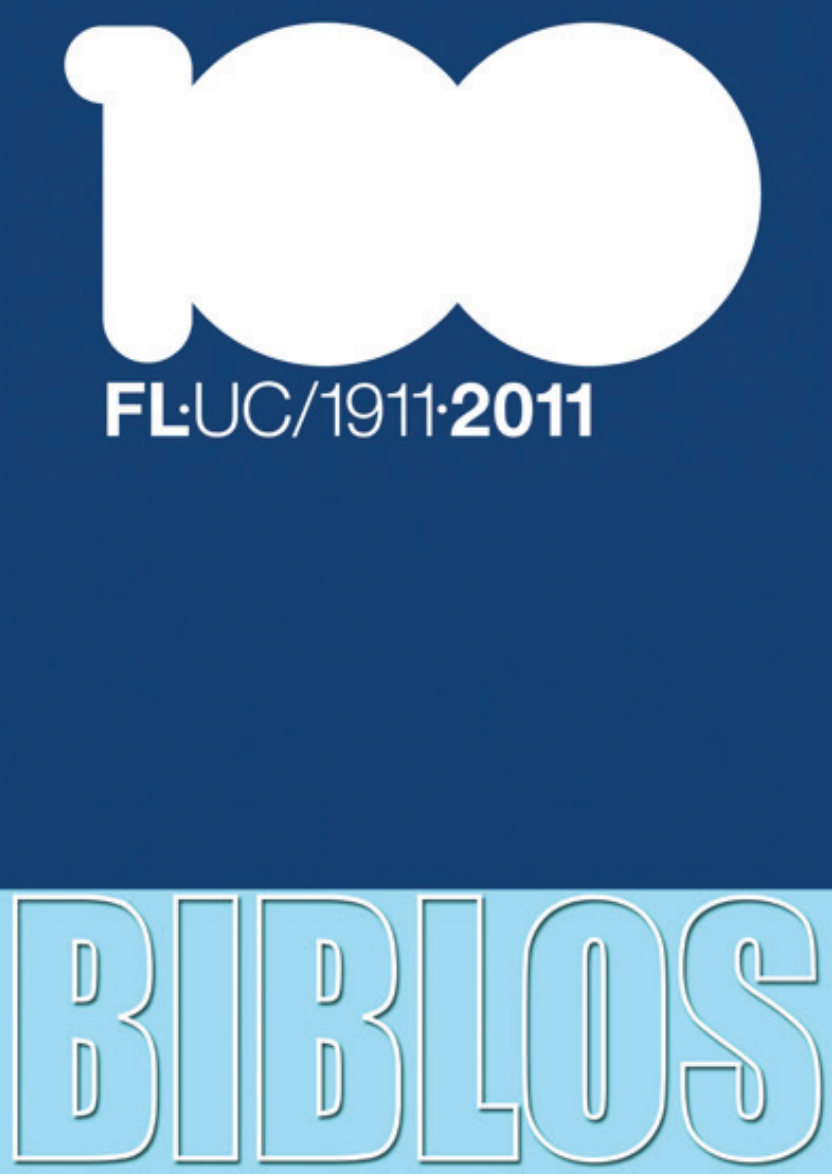

REVISTA DA FACULDADE DE LETRAS UNIVERSIDADE DE COIMBRA 
José D'EnCARnação

CEAUCP-Coimbra

\title{
A DISCIPLINA DE EPIGRAFIA NA FACULDADE DE LETRAS DE COIMBRA
}

\section{Resumo}

Panorâmica do que tem sido, na Faculdade, o ensino da Epigrafia, com particular realce para a figura do Padre Avelino de Jesus Costa. Dá-se conta das publicações, das iniciativas e dos projectos científicos, nacionais e internacionais, no domínio da Epigrafia, em que a Faculdade teve - e continua a ter - uma palavra a dizer.

Em apêndice, três exemplos: um texto egípcio, um epitáfio romano e uma invocação quinhentista.

Palavra-Chave: Epigrafia.

\begin{abstract}
This article presents an overview of the teaching of and research in Epigraphy at the Faculty of Arts and Humanities (University of Coimbra, Portugal), with a particular focus on the figure of Father Avelino de Jesus Costa. It gives an account of the publications, initiatives and national and international research projects in which the Faculty was - and continues to be - involved. Three examples are presented at the end: an Egyptian diploma, a Roman epitaph and a Christian invocation (1574).
\end{abstract}

Keyword: Epigraphy. 


\section{Introdução}

Desde cedo se instalou o hábito de fixar, pela escrita em materiais duradouros, as mensagens que se desejavam imorredoiras. Mensagem resultante de uma reflexão conjunta, fruto, portanto, dos mais variados circunstancialismos. Por conseguinte, bem depressa o escritor de História-mesmo quando a palavra ainda se não escrevia com maiúscula, o que lhe veio acentuar, a partir da $2^{\mathrm{a}}$ metade do século XIX (Gusdorf 1960 408-424), o carácter definitivo de ciência de pleno direito - se apercebeu do interesse da Epigrafia como fonte imprescindível para dar de uma época ou de um acontecimento o retrato mais fiel.

Também só é por essa altura que a Epigrafia começa a ser olhada como ciência, embora incluída no rol imenso das «ciências auxiliares da História»: Epigrafia, Arqueologia, Numismática, Esfragística, Codicologia, Paleografia e Diplomática, Papirologia... Tudo ciências hoje autónomas, porquanto se verificou que tinham também elas o seu objecto de estudo bem diferenciado, metodologia própria e objectivos precisos.

A primeira preocupação dos estudiosos (ou dos curiosos...) de Epigrafia foi a de decifrarem o que lá estava escrito. Amiúde, já pouco se via, gasta como estava a superfície epigrafada pelo passar dos tempos; frequentemente, o recurso a siglas e abreviaturas por parte de quem procedera à gravação dificultava ainda mais a compreensão, até porque se estava fora do contexto cronológico e, muitas vezes, até do espacial, de modo que mais complexa se tornava a tarefa.

Contudo, tal como na Paleografia havia as siglas e as abreviaturas do costume, o mesmo se passou a identificar nas epígrafes, para as diferentes épocas e situações. No que se prende, por exemplo, com as inscrições romanas, não foi difícil criar um rol válido dessas siglas e abreviaturas, até porque, dada a abundância de vestígios, textos havia em que os formulários vinham por extenso, facilitando, assim, a compreensão do que, noutros, surgia em siglas. Acentue-se, desde já, que foi, de modo particular, esse carácter de charada a decifrar, de mistério oculto, que constituiu a sedução suprema dessas 'pedras com letras' ou, para usar uma expressão hoje muito em voga, dessas «pedras que falam». ${ }^{1}$

${ }^{1}$ Usei-a no título do meu manual de Epigrafia (2010); foi subtítulo da magna exposição inaugurada, em 2002, no Museu Nacional de Arqueologia (Ribeiro 2002). 


\section{O ensino da Epigrafia}

A partir de um exaustivo trabalho prático elaborado, no ano lectivo de 1976-77, por três dos meus estudantes, ${ }^{2}$ que procuraram vasculhar os arquivos da Faculdade, já tive ensejo de traçar uma panorâmica (1982, 23-26) do que foi a leccionação desta disciplina na nossa Faculdade de Letras, designadamente até 1975, a exemplo, aliás, do que se passava em Lisboa e no Porto, uma vez que os programas eram gizados e uniformizados a nível nacional. ${ }^{3}$ E o panorama na Europa não era muito diverso, aliás. ${ }^{4}$

Duas notas, pois, importa salientar:

A primeira: no plano de estudos que vigorou, com mais ou menos adaptações pontuais, durante o Estado Novo, Epigrafia era, nas faculdades de letras, cadeira semestral aliada à Numismática, semestral também, que se leccionava a seguir, no $2^{\circ}$ ano do Curso de HistóricoGeográficas e, depois, de Histórico-Filosóficas e de História (somente a partir da década de 60). ${ }^{5}$ De resto, logo esta circunstância - de a História apenas se haver individualizado como curso universitário nos primeiros anos da década de 60 - permite compreender como essas «disciplinas afins» não poderiam ter um desenvolvimento específico, tanto no plano qualitativo como quantitativo, não sendo possível ao docente dar outra motivação que não a de inocular no estudante a ideia da importância da História para a compreensão da realidade e, paralelamente, a de incitar os mais dotados a fazerem acompanhar a sua carreira docente com uma actividade de investigação, que, nesses tempos, sempre seria complementar e não remunerada.

${ }^{2}$ Maria Cândida Corte-Real F. Cabral, António E. M. Rabaça de Carvalho e Maria Eduarda da Cunha do Vale.

3 Além desse primeiro texto, outras vezes abordei o tema: em 1988, 1999 e em 2010 (p. 55-58).

${ }^{4}$ Por sugestão minha, lançou Giancarlo Susini um inquérito às universidades europeias, de cujos resultados se fez eco na sua revista Epigraphica, de Bolonha: 461984 263-265. Idêntica vontade de saber o que se passara e passava esteve na origem do workshop sobre o ensino da Epigrafia, a que presidi, no XII Congresso Internacional de Epigrafia Grega e Latina (Barcelona, 03-08.09.2002), onde apresentei a comunicação intitulada «L'enseignement de l'Épigraphie au Portugal: la bataille et la guerre» (2007).

${ }^{5}$ Sei que nalgumas universidades europeias havia mesmo «Epigrafia e Numismática». 
A segunda nota visa evocar a extraordinária personalidade de Mestre do Padre Avelino de Jesus da Costa. Para além da Paleografia - a cujo incremento o seu nome fica perenemente ligado, por ter criado o Instituto de Paleografia e, com ele, despertado para esse domínio do saber uma plêiade de discípulos que, ainda hoje, erguem bem alto o nome da Faculdade em areópagos internacionais $-{ }^{6}{ }^{6}$ E Epigrafia constituiu o seu segundo «amor». Primeiro, porque, sendo sacerdote, mais facilmente penetrava na Epigrafia Romana e, de seguida, na Epigrafia Cristã que também particularmente lhe interessava, por ser um domínio então ainda pouco explorado. Por outro lado, a Paleografia, chave-mestra para entrar na escrita dos documentos medievais, em que tanto o Latim como as temáticas religiosas eram do quotidiano, enquadrava-se às mil maravilhas no seu universo de docente, de sacerdote e de investigador. E se o seu Álbum de Paleografia e Diplomática Portuguesas (Universidade de Coimbra, $1^{\text {a }}$ edição $1966,6^{\text {a }}$ 1997) constitui obra de consulta obrigatória para quantos queiram basear as suas pesquisas na documentação, por exemplo, das chancelarias régias, a sua sebenta

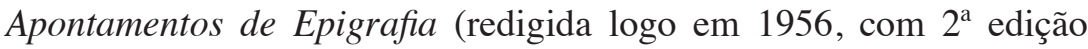
em 1972) (Fig. 1) foi autêntica 'pedrada no charco', manual singelo, metodologicamente bem estruturado, por onde era obrigatório aprender. ${ }^{7}$

Lançou, pois, Monsenhor Avelino (1908-2000) as bases do interesse pela Epigrafia, de que resultaria, v. g., a preparação de um punhado de dissertações de licenciatura.

${ }^{6}$ Permita-se-me que refira, entre outros, os Doutores Maria Helena da Cruz Coelho, Maria José Azevedo Santos, Saul António Gomes e Maria do Rosário Morujão, para citar três 'gerações' (digamos assim).

${ }^{7}$ Recorde-se que a $4^{a}$ edição (e última!) do clássico Cours d’Épigraphie Latine, de René Cagnat, data de Paris, 1914; e que o primeiro livro acessível e de ampla divulgação desta disciplina se deve a Raymond Bloch (1952). Sobre a actividade científica do Cónego Avelino, podem ver-se os depoimentos publicados no fascículo 2 do $\mathrm{n}^{\circ} 28$ (1993) da revista Theologica, que lhe foi dedicado: «Professor Doutor Avelino de Jesus da Costa. Sinopse bio-bibliográfica», de José Marques (p. 285-304) e «Bibliografia de Avelino de Jesus da Costa», de Arminda Clara Poças (p. 305-338). E ainda: Coelho 1990. 


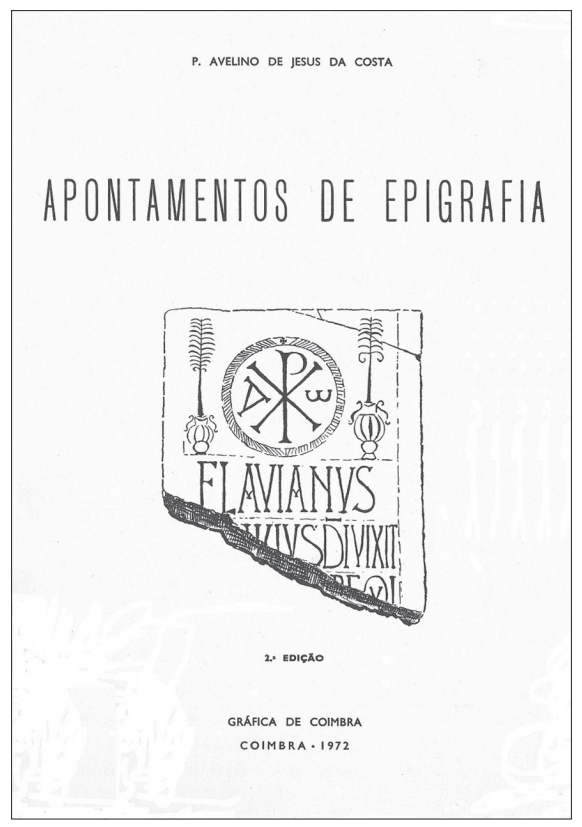

Figura 1 -Apontamentos de Epigrafia

\section{Após a Revolução de Abril}

Pôde a Universidade, após a Revolução de Abril de 1974, lançar mãos a profundas reformas dos seus currículos. Para além de se aceitar a divisão das Histórias em Económica e Social, Cultural e das Mentalidades, e também - para satisfazer os que haviam saído do anterior ramo das Histórico-Filosóficas e pendiam mais para uma Filosofia da História... - em História e Teoria das Ideias, cada uma com suas cadeiras próprias em cada época (Medieval, Moderna e Contemporânea), optou-se por dividir os anteriores cinco anos em dois ciclos, digamos assim: num primeiro, grosso modo equivalente ao que se chamaria o bacharelato, de três anos, seriam ministrados conhecimentos gerais; havia, no segundo, uma pré-especialização. E é aí que entra a Epigrafia, na Pré-Especialização em Arqueologia.

Com uma importante característica: ser anual. Pela primeira vez e julgo não errar se afirmar que também nisso fomos pioneiros - uma cadeira tida como «auxiliar da História» ganhava foros de disciplina de 
pleno direito num currículo académico. Para essa decisão contribuíram, não duvido, o facto de se estar a preparar, nessa altura, o volume II das Fouilles de Conimbriga (Étienne et alii, 1976), o primeiro livro que estudava o monumento epigráfico em todos os seus aspectos. Essa análise global permitira lançar nova luz sobre a sociedade conimbricense e abria, sem dúvida, inovadoras perspectivas de investigação. Aliás, já no volume de 1972 da revista Conimbriga D. Domingos de Pinho Brandão estudara a epigrafia de Collipo, uma cidade a cuja descoberta e escavação o Instituto de Arqueologia também estivera intimamente ligado (Oleiro e Alarcão, 1969).

A criação dessa cadeira anual, em 1975-1976, unida à circunstância de estar inserida numa pré-especialização, ou seja, com estudantes já maduros e bem conscientes do que queriam fazer na vida proporcionou, pois, todas as condições para que se fizessem trabalhos práticos que redundaram em grande surpresa, pois que se verificou haver por aí, mesmo em museus, inscrições romanas inéditas e outras cuja leitura e interpretação importava rever. Daí que vários dos que foram depois docentes da Faculdade (e doutras Escolas) tenham visto publicado no âmbito da Epigrafia o seu primeiro trabalho científico, resultante da investigação que haviam feito para a cadeira ${ }^{8} \mathrm{E}$ a revista Conimbriga deu, de imediato, abrigo a uma série de artigos sobre temas epigráficos, inseridos - diga-se também, em abono da verdade - no rumo que a «escola de Coimbra» se propunha seguir, para se distinguir de Lisboa e do Porto e para manter a tradição de ligação profunda a uma cidade romana: a Arqueologia Romana. Aliás, para dar a conhecer esses novos monumentos optou-se por criar, em 1982, o Ficheiro Epigráfico. ${ }^{9}$

Para apoio dos estudantes e para lhes dar conta das novas orientações, cedo se sentiu a necessidade de fazer um manual de Epigrafia Latina (Encarnação 1979, 1987 e 1997), ora bastante remodelado (2006 e 2010); e fez-se nova edição de um manual clássico de Epigrafia Portuguesa há muito esgotado (Sousa 1983).

Factor decisivo para o desenvolvimento da disciplina foi, igualmente, a internacionalização, conseguida através da participação, em Setembro

${ }^{8}$ Veja-se, a título de exemplo: Borges 1976, Moreira 1976, Vaz 1977, Monteiro 1980, Anacleto 1981, Mantas 1982.

${ }^{9}$ Cf. Encarnação 1988a. Até 2010, publicou 90 números, num total superior a 420 epígrafes inéditas. 
de 1977, no VII Congrès International d'Épigraphie Grecque et Latine, em Constanza (Roménia), onde houve a possibilidade de contactar com os maiores epigrafistas da actualidade e dar-lhes a conhecer a actividade a que se estava metendo ombros. Aliás, a inclusão, nessa data, do nome de Coimbra na Association Internationale d'Épigraphie Grecque et Latine funcionou, por seu turno, como outra alavanca, dado que, a esse nível, Portugal... não existia - e passou a existir!

Papel importante desempenhou, não o podemos esquecer, a ligação íntima do Instituto de Arqueologia com o Centre Pierre Paris, da Universidade de Bordéus III. De certo modo para complementar o programa lançado pela Academia das Ciências de Berlim, de fazer um novo CIL II, tinha Robert Étienne o projecto de estudar toda a epigrafia romana peninsular, mediante a publicação de corpora regionais, dado que, inclusive, fomentara, para o efeito, a criação de uma base de dados original (Étienne 1977). O I volume dessa série foi o das inscrições romanas de Lugo (Arias Vilas et alii 1979); a minha dissertação de doutoramento (1984) vem nessa mesma linha e, embora sem a regularidade que se previra, outros volumes se seguiram, no âmbito geográfico espanhol, estando na forja (digamos assim) o do Norte de Portugal, em que intervém o nosso ex-aluno Armando Redentor. A Mesa-Redonda Internacional sobre Épigraphie Hispanique - Problèmes de Méthode et d'Édition, reunida em Bordéus, em Dezembro de 1981, insere-se em pleno nessa perspectiva de investigação.

E se Robert Étienne orientara os seus colaboradores para - mormente com base nos dados epigráficos - fazerem sobre a Península Ibérica as suas dissertações de doutoramento, ${ }^{10}$ Jorge Alarcão levou os seus doutorandos a estudarem as cidades romanas, com particular destaque para os seus monumentos epigráficos. ${ }^{11} \mathrm{E}$ vários dos nossos estudantes tiveram, pois, a possibilidade de, no âmbito do Programa ERASMUS, passar um ano (ou um semestre) em universidades onde os estudos epigráficos eram da mais elevada qualidade: o já citado Centre Pierre Paris (Bordéus III), Bolonha (onde pontificavam o grande mestre Giancarlo Susini e Ângela Donati), Sassari, Poitiers, Barcelona...

\footnotetext{
${ }^{10}$ Cfr. os exemplos que se mencionam em Encarnação 2010a, p. 385-386.

${ }^{11}$ Vaz 1997, Bernardes 2001. Por publicar está a tese de Vasco Mantas (A Rede Viária Romana da Faixa Atlântica entre Lisboa e Braga, Coimbra, 1997), também ela assente em muita documentação epigráfica.
} 


\section{Perspectivas}

O prestígio e o reconhecimento, a nível nacional e internacional, da actividade desenvolvida na Faculdade de Letras da Universidade de Coimbra determinaram que facilmente se tenham aceitado as candidaturas para a realização em Portugal, sob sua orientação ou co-orientação, reuniões científicas internacionais, ligadas aos grupos de investigação em que gostosamente nos envolvemos. ${ }^{12}$

Perante a visão economicista dominante, poderia pensar-se que uma investigação em Epigrafia tinha os seus dias contados, até porque a dita «reforma de Bolonha», por ter alinhado, por inteiro, numa visão da Humanidade de que o Homem (exacto, com maiúscula) parece ter sido arredado, acabou por atirar de novo a disciplina para o «Lago do Esquecimento»...

É possível, porém, ver o futuro doutra forma. A semente lançada poderá vir a germinar e a dar bons frutos, mau grado a pedregosidade dos caminhos...

$\mathrm{Na}$ verdade, a publicidade enche os nossos dias e a «epigrafia» tem nela um lugar predominante. Os políticos não prescindem de descerrar lápides - que entram, de pleno direito, na História. Depressa se aprenderá que medidas económicas sem pessoas e sem cultura estão destinadas ao fracasso; rapidamente se consciencializará também que, ao querer-se nome gravado numa lápide para a solenidade de uma inauguração, uma simples passagem ou efeméride especial, se está a fabricar uma 'epígrafe', duradoura fonte histórica para a posteridade. O fulgor dos discursos e o calor dos aplausos obnubilarão, quiçá, o acto em si; um dia, porém, esquecidos uns e outros, mui longínquos já os ecos de eventual foguetório, hão-de aperceber-se as gentes de que, afinal, o que de tudo restou foi aquela singela pedra ali, cravada em muro, que,

${ }^{12}$ II Congresso Peninsular de História Antiga (Coimbra, 18-20.10.1990); VI Colóquio sobre Línguas e Culturas Paleo-hispânicas (Coimbra e Figueira da Foz,13-15.10.1994); VI Mesa-Redonda sobre a Lusitânia Romana (Cascais, 04-06.11.2004); VII Workshop FERCAN (Cascais, 25-27-05-2006); X Colóquio Internacional sobre Línguas e Culturas Paleo-hispânicas (no Museu Nacional de Arqueologia, Lisboa, 26.28-02-2009). De todos se publicaram as actas. FERCAN é a sigla de um projecto de investigação em que estamos integrados (Fontes Epigraphici Religionum Celticarum Antiquarum), coordenado pelo Prof. Hainzmann, da Universidade de Graz (Áustria). 
por via dela, nunca o será de silêncio! Diante dela se reflectirá, pois: estes são os dizeres explícitos; mas... que honras, que razões, que ideologia lhe estão realmente por detrás? Uma reflexão... epigráfica!

E se até os cemitérios - onde as pedras com letras são rainhas!... estão a ser alvo, agora, de atenção do ponto de vista histórico-cultural, garantia há, por conseguinte, de que a Epigrafia é disciplina científica em que a Faculdade de Letras de Coimbra teve - e sempre continuará a ter - uma palavra a dizer!

\section{Apêndice}

\section{Os hieróglifos (Fig. 2)}

Não será difícil perceber como, no Egipto antigo, parece que havia um horror ao vazio: as paredes de túmulos e de templos tinham de estar profusamente decoradas e escritas. A foto - que fiz a 28-12-2006 - representa a parte superior da chamada estela de Naucratis, um dos cerca de 500 objectos (dos quais 489 estátuas!...) recuperados no decorrer das escavações subaquáticas levadas a efeito, desde 1996, ao largo de Alexandria e na baía de Aboukir por Franck Goddio e que constituíram a exposição Trésors engloutis d'Égypte, patente, de 9 de Dezembro de 2006 a 16 de Março de 2007, no Grand Palais, em Paris.

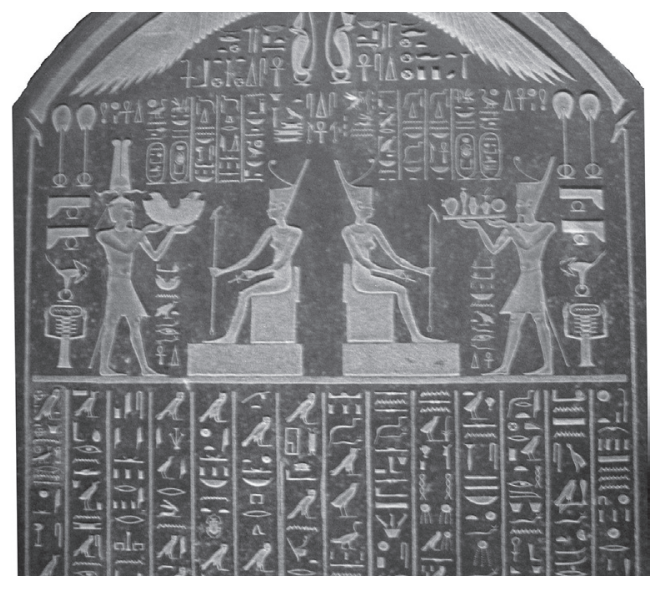

Figura 2 - Os hieróglifos 
As imagens representam Nectanebo a oferecer, em ritual, uma gargantilha recipientes (certamente com perfumes e especiarias) à deusa Neith. O texto, bastante longo e pormenorizado, hieróglifos apenas compreensíveis por egiptólogos, é o decreto feito pelo rei, aquando de uma sua visita a Sais (a cidade de Neith), que estabelecia uma taxa sobre as mercadorias que passassem pelo entreposto grego de Naucratis. Na realidade, tal determinação - assim solenemente gravada em imponente estela - não é de estranhar, na medida em que se sabe que, através do braço Canópico do Nilo, esses produtos transitavam por Thonis/ /Heráklion. Decreto de tamanha importância tinha, pois, de ficar gravado em material duradoiro, inclusive para figurar em lugar público!...

\section{Uma urna cinerária (Fig. 3)}

Ao visitar o Pergamon, em Berlim, a 27 de Maio de 2005, chamou-me a atenção esta urna cinerária de mármore, que, pela sua beleza (evoca a fachada bem decorada de um templo...), agora se me afigurou susceptível de apresentar aqui, a título de exemplo do tipo de investigação que pode suscitar.

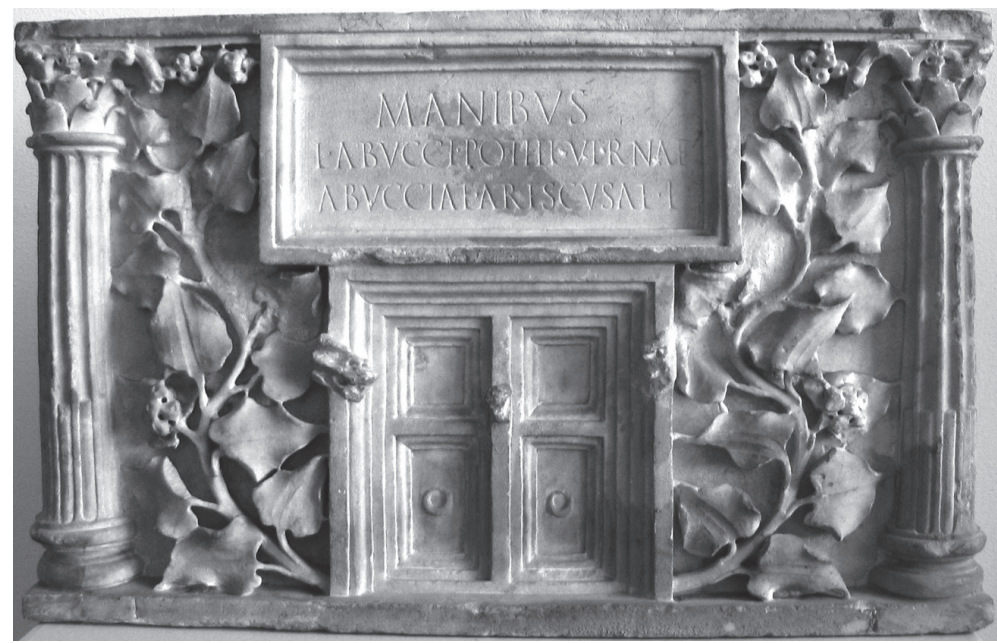

Figura 3 - Uma urna cinerária 
Não tomei, então, nota nem da proveniência nem de eventuais estudos que sobre ela houvessem sido feitos, pelo que, perante apenas a fotografia, iniciei a caminhada.

Primeiro, a leitura interpretada:

MANIBVS / L $(u c i i) \cdot \operatorname{ABVCCI}(i) \cdot \mathrm{POTHI} \cdot \mathrm{VERNAE} / \mathrm{ABVCCIAE}$ $\cdot$ ARESCVSAE $\cdot$ L(ibertae).

O que significa:

Aos Manes de Lúcio Abúcio Poto, escravo nascido em casa do senhor; de Abúcia Arescusa, liberta.

Não havendo a conjunção et (e), poderíamos ter alguma hesitação: se estaríamos mesmo perante a urna cinerária de duas pessoas. Caso não o fosse, poderia concluir-se que Arescusa teria sido liberta de Poto, o que não é, porém, verosímil, dado que Poto é identificado como escravo. São, pois, dois membros da mesma família.

Uma pesquisa por corpora e dicionários trouxe-me de imediato L. Abúcio, proprietário de uma herdade perto de Alba, homem ilustrado, autor de poemas satíricos, de que fala Varrão (Res Rusticae, 3.2.17). Pela identidade do primeiro nome (praenomen), será, pois, dessa família.

Um pouco mais de investigação levou-me à informação mais completa: esta 'arca marmorea litteris pulchris' (as letras estão muito bem desenhadas) terá certamente pertencido a um grande monumento funerário da cidade de Roma («monumentum familiae Abucciorum», com mais de cinquenta epitáfios $-\mathrm{n}^{\text {os }} 8117$ a 8172), tendo sido incluído no Corpus Inscriptionum Latinarum da Cidade Eterna: CIL VI $\mathrm{n}^{\circ}$ 8171. O Cardeal de Polignac levou-a para Paris em 1732 e daí saiu para o Museu de Berlim, onde a identifiquei. Um percurso que não é de estranhar, atendendo à graciosidade da urna e facilidade do seu transporte.

Datável do século I da nossa era, mormente pela paleografia e pela simplicidade do texto, refere-se a personagens de origem servil, que ostentam nomes típicos dessa condição. Assim, Arescusa deriva

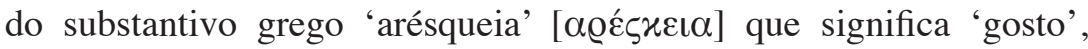
'prazer', 'agrado'; ou seja, seria bem agradável estar com ela!... No conjunto da epigrafia de Roma compulsado por Solin (p. 863-864), num total de 70 testemunhos, 31 identificam escravos ou libertos. Quanto a Pothus, nome que identifica 20 escravos e/ou libertos num total de 42 testemunhos em Roma (Solin, 440), estará certamente relacionado com a palavra grega Jó $\theta$ oo, 'desejo', 'paixão, 'luxúria'... 


\section{Lintel de porta albicastrense (Fig. 4)}

Mão amiga me ofereceu, vai para 30 anos, esta foto do lintel da porta 34 de uma rua do centro histórico de Castelo Branco.

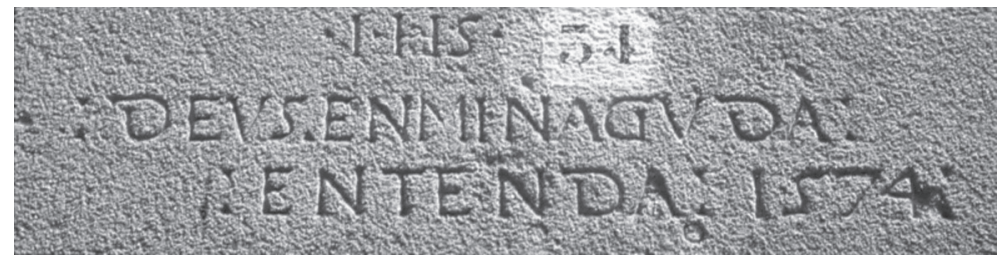

Figura 4 - Lintel de porta albicastrense

$\cdot \mathrm{I} \cdot \mathrm{H} \cdot \mathrm{S} \cdot$

: DEVS.ENMIÑAGVDA :

: ENTENDA : 1574 :

Parecia estranha essa legenda nele gravada e, em troca de impressões com o Padre Nogueira Gonçalves, de pronto ele me deu a solução do enigma: trata-se de um aportuguesamento da invocação Deus in adiutorium meum intende, amiúde usada nas cerimónias litúrgicas católicas, a que se responde Domine ad adjuvandum me festina. Trata-se do versículo 2 do Salmo 69: «Ó Deus, vem em meu auxílio! Apressa-Te, Senhor, a socorrer-me!».

De diversos pontos de vista se pode analisar esta epígrafe, expressamente datada de 1574.

Em primeiro lugar, o hábito, nessa época da Contra-Reforma, de assim se procurar obter apoio divino, mormente mediante a gravação do monograma IHS, adoptado por S. Inácio de Loiola como emblema da Companhia de Jesus, que fundara (1541). São as três primeiras letras, em maiúsculas do alfabeto grego, da palavra Jesus - e não, como por vezes se ouve referir, três siglas a desdobrar em Iesus Hominum Salvator, 'Jesus, salvador dos homens'. Por conseguinte, estamos, para já, perante um indício forte da influência jesuítica, paladina, como se sabe, do retorno ao Cristianismo autêntico, abalado então pelos movimentos reformistas.

Depois - e esse será, sem dúvida, um dos aspectos mais sedutores para o epigrafista e, conseguintemente, para o historiador da cultura -, a manifesta influência da oralidade. As cerimónias religiosas eram 
em Latim (foram-no, aliás, até ao Concílio do Vaticano II, em 1962-1965) e os fiéis entendiam o significado das frases, mas desconhecia a maior parte como poderia ser a sua tradução em português! Adiutorium era palavra erudita de mais; em vez dela, portanto, optou-se por uma mais do cotio: ajuda (ainda que mal grafada, com g). Intende também não seria lá muito compreensível no seu significado de «está atento», «atende», «vem»... «Entender» tinha um som semelhante e, de resto, o que, na verdade, se pretendia era que o Senhor 'entendesse' ou 'atendesse' a protecção que se Lhe pedia... Por outro lado, ainda hoje se tem algum pejo em traduzir à letra passagens da Bíblia em que haja uma invocação à divindade: diz-se «Vinde em meu auxílio», quando, no texto original, é a segunda pessoa do singular que se encontra. Daí também a forma «ENTENDA», numa terceira pessoa a concordar com Deus, num voto e não numa prece.

São, como se imagina, às centenas - se não mesmo aos milhares letreiros destes que subsistem pelas nossas cidades, vilas e aldeias. Toda a gente os vê; poucos lhes ligam importância, preservando-os; cada vez mais deveriam ser os que tomam consciência do seu real interesse como fontes históricas que, indemnes, sobreviveram séculos afora!

\section{Bibliografia}

ANACLETO, Regina (1981), Bobadela Epigráfica, Coimbra.

ARIAS VILAS, Felipe, LE ROUX, Patrick, et TRANOY, Alain (1979), Inscriptions Romaines de la Province de Lugo, Paris.

BERNARDES, João Pedro (2007), A Ocupação Romana de Leiria, Faro.

BLOCH, Raymond (1952), L'Épigraphie Latine, PUF, Col. Que sais-je? ( $\left.\mathrm{n}^{\mathrm{o}} 534\right)$, Paris.

BORGES, Nelson Correia (1976), «Nova leitura da inscrição CIL 6275a (Penacova)», Conimbriga 15 117-125.

BRANDÃO, D. Domingos Pinho (1972), «Epigrafia romana coliponense», Conimbriga 11 41-192.

COELHO, Maria Helena da Cruz (1990), «Doutor Cónego Avelino de Jesus da Costa: O Professor, o Mestre», Revista Portuguesa de História, 25, 309-317. Acessível em: http://hdl.handle.net/10316/ 12675 . 
ENCARNAÇÃO, José d', Introdução ao Estudo da Epigrafia Latina, Coimbra, ${ }^{1} 1979,{ }^{2} 1987,{ }^{3} 1997$.

ENCARNAÇÃO, José d' (1982), «O ensino da Epigrafia em Portugal», Munda 3 (Maio 1982) 23-26.

ENCARNAÇÃO, José d' (1984), Inscrições Romanas do Conventus Pacensis - Subsídios para o Estudo da Romanização, Coimbra.

ENCARNAÇÃO, José d' (1988), «Epigrafia em Portugal, ciência antiga, rumos novos», Arqueologia 17 (Junho 1988) 204-207 [versão actualizada do texto inserto in Os Portugueses e o Mundo, Porto, 1989, 6, 149-155].

ENCARNAÇÃO, José d' (1988a), «Ficheiro Epigráfico - uma experiência em curso em Portugal», Trabalhos de Antropologia e Etnologia 27 245-247.

ENCARNAÇÃO, José d' (1999), «O ensino da Epigrafia», Arqueologia e História 51 197-203.

ENCARNAÇÃO, José d' (2007), «L'Épigraphie au Portugal - enseignement: la bataille et la guerre», in MAYER I OLIVÉ, Marc, BARATTA, Giulia, e GUZMÁN ALMAGRO, Alejandra [edit.], Acta XII Congressus Internationalis Epigraphiae Graecae et Latinae, Barcelona, 363-364.

ENCARNAÇÃO, José d' (2010), Epigrafia - As Pedras que Falam, Imprensa da Universidade de Coimbra, ${ }^{12006},{ }^{2} 2010$.

ENCARNAÇÃO,José d' (2010a), «O miliário como documento»,Pallas 82 385-394. Acessível em: http://hdl.handle.net/10316/13349.

Épigraphie Hispanique - Problèmes de Méthode et d'Édition, De Boccard, Paris, 1984.

ÉTIENNE, Robert (1977), «Le Centre Pierre Paris (ERA 522) et la révision des inscriptions grecques et latines de la Péninsule Ibérique», Conimbriga 16 83-88.

ÉTIENNE, Robert, FABRE, Georges, et LÉVÊQUE, Pierre et Monique (1976), Fouilles de Conimbriga, II - Épigraphie et Sculpture, Paris.

GUSDORF, Georges (1960), Introduction aux Sciences Humaines, Paris, Belles Lettres.

MANTAS, Vasco Gil (1982), «Inscrições romanas do Museu Municipal de Torres Vedras», Conimbriga 21 5-99.

MONTEIRO, António João Nunes (1980), «Duas inscrições inéditas encontradas em Serpins (Lousã)», Conimbriga 191980 163-172. 
MOREIRA, José Beleza (1976), «Duas inscrições funerárias romanas na igreja de S. Lourenço dos Francos», Conimbriga 15 127-131.

OLEIRO, João Manuel Bairrão e ALARCÃO, Jorge de (1969), «Escavações em S. Sebastião do Freixo, concelho da Batalha», Conimbriga 8 1-12.

RIBEIRO, José Cardim [coord.] (2002), Religiões da Lusitânia. Loquuntur Saxa, Museu Nacional de Arqueologia, Lisboa.

SOLIN, Heikki (1982), Die griechischen Personennamen in Rom. Ein Namenbuch, 1, Berlin-Nova Iorque.

SOUSA, José Maria Cordeiro de (1983), Apontamentos de Epigrafia Portuguesa, Coimbra, Instituto de Arqueologia, ${ }^{4} 1983$.

VAZ, João Luís I. (1977 e 1978), «Inscrições romanas do museu do Fundão», Conimbriga 16 5-32 e 17 60-61 (adenda).

VAZ, João Luís Inês (1997), A Civitas de Viseu - Espaço e Sociedade, Coimbra. 